\title{
SISTEM PENDUKUNG KEPUTUSAN KELOMPOK DENGAN METODE NOMINAL GROUP TECHNIQUE (NGT) BERBASIS WEB (STUDI KASUS: ORGANISASI GEPAK KORWIL SAMARINDA ULU)
}

\author{
Dewi Susanti' ${ }^{1)}$, Muhamad Azhari' ${ }^{2)}$, Dyna Marisa Khairina ${ }^{3)}$ \\ ${ }^{1,2,3)}$ Program Studi Ilmu Komputer, Fakultas Ilmu Komputer dan Teknologi Informasi, Universitas Mulawarman \\ Jalan Barong Tongkok Kampus Gunung Kelua Samarinda, Kalimantan Timur \\ Email : susanti.dewi515@yahoo.com ${ }^{1)}$, m4zh4ri@gmail.com ${ }^{2}$, dyna.ilkom@gmail.com ${ }^{3)}$
}

\begin{abstract}
ABSTRAK
Group Support System (GSS) ialah system pendukung keputusan kelompok yang digunakan untuk menghasilkan alternative solusi dari para anggota untuk rekomendasi seorang manajer dalam menghasilkan keputusan. Metode Nominal Group Technique (NGT) ialah metode yang dikembangkan untuk menghasilkan solusi dengan tingkat efektif yang tinggi baik dari segi membangkitkan ide/gagasan maupun tingkat partisipasi. Web sendiri adalah teknologi jaringan yang menunjang berbagai interaksi social terjalin secara luas. Organisasi Gerakan Pemuda Asli Kalimantan (GEPAK) ialah organisasi etnis yang memiliki maksud dan tujuan untuk meningkatkan kualitas SDM agar dapat mengelola SDA di Kalimantan. Sehingga Sistem Pendukung Keputusan Kelompok Dengan Metode Nominal Group Technique (NGT) Berbasis Web menjadi system pendukung keputusan yang membantu manajer dari Organisasi GEPAK untuk melakukan rapat dan diskusi secara efektif dan efisien baik dari segi waktu dan biaya.
\end{abstract}

Kata kunci : GSS, Nominal Group Technique (NGT), Web, Organisasi

\section{PENDAHULUAN}

Film merupakan salah satu media komunikasi modern yang efektif berbentuk audio visual dan sifatnya sangat kompleks. Film merupakan hasil karya yang sangat unik dan menarik, karena menuangkan gagasan dalam bentuk gambar hidup sekaligus sebagai informasi yang dapat menjadi alat penghibur, propaganda, juga sebagai politik, serta dapat menjadi sarana rekreasi dan edukasi yang layak dinikmati oleh masyarakat. Di sisi lain, film juga dapat berperan sebagai penyebarluasan terhadap nilai budaya. Tetapi dalam pembuatan film harus memiliki daya tarik tersendiri, sehingga pesan moral yang akan disampaikan bisa ditangkap oleh penonton.

Film disebut sebagai sinema atau gambar hidup yang diartikan sebagai karya seni dan merupakan bentuk populer dari hiburan, produksi industri atau barang bisnis. Film sebagai karya seni yang lahir dari proses kreatifitas yang menuntut kebebasan berkreativitas.

Film biasa dikategorikan menurut genrenya. Sebuah film bisa juga memiliki lebih dari satu genre. Ada beberapa macam yang dikenal oleh masyarakat luas. Beberapa contohnya adalah genre film action, animation, comedy, musical, sciencefiction, dan horror. Ada beberapa unsur lain yang memuat berbagai informasi mengenai film itu sendiri, misalnya judul film, tahun rilis, sinopsis, pemain, direktor, penghargaan, durasi, poster dan catatan film.

Seiring berkembangnya teknologi dewasa ini, perkembangan film bergerak sangat cepat dari gambar bergerak, teknologi yang memadukan gambar dan suara, teknologi film berwarna sampai ditemukannya teknologi DVD (Digital Versatile Disc). Hingga saat ini film berbentuk file lebih populer karena sangat mudah didapatkan dan praktis dalam penggunaannya, sehingga banyak digemari masyarakat dan menjadikan popularitas film semakin meningkat. Banyak kolektor film yang memanfaatkan keadaan ini dengan mengkoleksi lebih banyak film. Masalah yang timbul sebagai kolektor adalah bagaimana cara memanajemen setiap film berdasarkan genre atau tahunnya, serta menambahkan catatan informasi dari setiap film.

Berdasarkan latar belakang tersebut maka akan dibuat aplikasi sistem informasi yang memudahkan manajemen koleksi film menggunakan teknik web scrapping.

\section{TINJAUAN PUSTAKA}

a. Film

Film adalah selaput tipis yang dibuat dari seluloid untuk tempat gambar negatif (yang akan dibuat potret) atau untuk tempat gambar positif (yang akan dimainkan di bioskop). Film juga diartikan sebagai lakon (cerita) gambar hidup [1].

Film memiliki banyak keunggulan. Film mampu menampilkan objek yang tidak bisa dilihat secara mata telanjang. Film mampu memvisualkan objek yang terlalu besar, objek yang sangat kecil, memperlambat gerakan objek yang terlalu cepat atau sebaliknya, mempercepat gerakan objek yang terlalu lambat. Dengan teknologi efek, animasi dan tata suara tertentu, film mampu memberikan kesan lebih dramatis daripada kejadian yang sebenarnya. Singkat kata, dengan film sesuatu yang tidak mungkin jadi sangat mungkin [2]. 


\section{b. Sejarah Film}

Sejak awal abad ke-19 dilakukan berbagai percobaan untuk menciptakan sebuah pesawat yang dapat memancarkan gambar yang dapat bergerak. Langkah pertama ke arah cinematografi dilakukan oleh E. Muybridge, seorang petualang Inggris yang berimigrasi ke California pada tahun 1849.Awalnya adalah kegemaran bertaruh balapan kuda.Pada tahun 1977, Muybridge menempatkan 12 kamera sepanjang jalur lapangan, dan merentangkan talitali menyeberangi jalur. Setiap melewatinya kuda diabadikan oleh satu kamera. Muybridge merealisasikan semua gerakan asli dan memproyeksikannya dengan lentera ajaib. Selama 20 tahun sejak itu, Muybridge meneruskan pengambilan gambar bergerak.Pada tahun 1882 seorang Perancis bernama Etienne Jules Marey, mengambil gambar bergerak dengan satu kamera. Ide ini diambil dari ide Muybridge. Marey membuat sebuah senapan yang dapat menampilkan 12 gambar dalam satu detik [3].

Perkembangan film bergerak dan berlanjut dengan cepat, apalagi setelah penemuan film negatif transparan. Perkembangan terus berlanjut dengan ditemukannya mesin-mesin sinema pertama. Pada tahun 1888, Thomas A. Edison menemukan kamera gambar bergerak yang bernama kinematografi. Kemudian tahun 1985 dua bersaudara Perancis, Auguste dan Louis Lumiere (dikenal dengan Lumiere bersaudara), mengembangkan penemuan Edison sehingga ditemukan peralatan yang dapat mengambil gambar bergerak (film), memperbanyak, serta memproyeksikan ke layer (screen play).

Pada Perang Dunia I, teknologi perfilmanpun mencapai kesempurnaan, sampai kemudian ditemukan teknologi yang mampu memadukan gambar dan suara (1926-1930), suatu penemuan yang menandakan berakhirnya periode film bisu. Kemudian teknologi film berwarna semakin memacu gairah para masyarakat film.Juga berkembangnya film-film untuk siaran televisi dan film-film tiga dimensi. Dalam teknologi suara muncul teknologi dolby stereo yang membuat suara film bermunculan di semua sisi gedung bioskop.

\section{c. Klasifikasi Film}

Film dalam batasan sinematografi sepanjang sejarahnya memberikan keluasan tema bila dilihat dari isi dan sasaran tujuannya. Di dalam pedoman pelaksanaan FFI (Festifal Film Indonesia) yang ditetapkan oleh Menteri Penerangan dengan SK 27/A/Kep/Menpen/83 pada tanggal 14 Maret 1983 ada beberapa jenis film, diantaranya:

1. Film dokumenter

2. Film ilmu pengetahuan/pendidikan

3. Film kartun

4. Film yang tidak digolongkan sebagi film cerita.
Terlepas dari empat jenis film di atas, di bawah ini penulis akan menyebutkan bebagai jenis film yang lain, diantaranya, film Action, Animation, Adventure, Comedy, Fantasy, Horror, Musical, Science-Fiction, War, Western.

\section{d. Manajemen}

Secara etimologis kata manajemen berasal dari bahasa Perancis Kuno ménagement, yang berarti seni melaksanakan dan mengatur.Sedangkan secara terminologis para pakar mendefinisikan manajemen secara beragam.

Pengertian manajemen telah banyak dibahas para ahli yang antara satu dengan yang lain saling melengkapi. Stoner yang dikutip oleh Handoko menyatakan bahwa manajemen merupakan proses perencanan, pengorganisasian, pengarahan, dan pengawasan, usaha-usaha para anggota organisasi dan pengguna sumber daya organisasi lainya untuk mencapai tujuan organisasi yang telah ditetapkan. Stoner menekanan bahwa manajemen dititik beratkan pada proses dan sistem. Oleh karena itu, apabila dalam sistem dan proses perencanaan, pengorganisasian, pengarahan, penganggaran, dan sistem pengawasan tidak baik, proses manajemen secara keseluruhan tidak lancar sehingga proses pencapaian tujuan akan terganggu atau mengalami kegagalan [4].

Fungsi manajemen dapat dibagi menjadi empat bagian, yakni planning (perencanaan), organizing (pengorganisasian), actuating (pelaksanaan), dan controlling (pengawasan) [5]:

\section{e. Web Scrapping}

Web Scrapping atau Screen Scrapping adalah suatu teknik dimana suatu program dalam komputer mengutip data dari tampilan keluaran program lain, dan program yang melakukannya disebut screen scraper. Yang membedakannya dengan parsing biasa adalah dimana untuk screen scrapping ini datanya lebih diperuntukkan untuk ditampilkan ke pengguna akhir daripada untuk inputan program lain. Screen scrapping sering mengabaikan data biner (biasanya foto atau data multimedia) dan format elemennya, sehingga cenderung pada data penting berupa teks.

Umumnya transfer data antara program dilakukan dengan struktur data yang cocok untuk diproses secara otomatis dengan komputer, seperti pada pertukaran format dan protocol yang berstruktur kaku, didokumentasikan dengan baik. Seringnya transmisi ini tidak dibaca manusia sama sekali. Tetapi untuk output yang berkebalikan dengan hal di atas seperti label yang berlebih atau komentar yang berlebih atau informasi lainnya yang tidak dapat dilakukan dengan proses otomasi. Akan tetapi, meskipun output yang tersedia adalah sebuah tampilan untuk manusia, screen scrapping menjadi suatu cara untuk mengerjakan transfer data tersebut. [6]. 


\section{f. Microsoft Access}

Microsoft Access adalah sebuah program aplikasi basis data komputer relasional yang ditujukan untuk kalangan rumahan dan perusahaan kecil hingga menengah. Aplikasi ini merupakan anggota dari beberapa aplikasi Microsoft Office, selain tentunya Microsoft Word, Microsoft Excel, dan Microsoft PowerPoint. Aplikasi ini menggunakan mesin basis data Microsoft Jet Database Engine, dan juga menggunakan tampilan grafis yang intuitif sehingga memudahkan pengguna.

Sekarang ini Microsoft meluncurkan Versi baru dari Microsoft Access 2007, ada banyak perbedaan dengan versi lamanya.Sekilas tampilan Microsoft Access2007 sangat berbeda dengan Microsoft Access 2003, versi baru ini menawarkan kemudahan penggunaan bagi para pengguna. Akan tetapi, di balik kemudahannya tersebut, versi ini mempunyai kemampuan baru yang lebih handal tentunya. [7].

\section{g. API (Application Programming Interface)}

Appication Programming Interface (API) adalah sekumpulan fungsi, perintah dan protokol yang dapat digunakan untuk menghubungkan satu aplikasi dengan aplikasi yang lain agar dapat berinteraksi. Seiring dengan perkembangan internet, API dapat diimplementasikan pada sisi server dan dapat digunakan oleh beberapa aplikasi yang dapat terhubung ke server dengan menggunakan protokol tertentu. Pada protokol HTTP, Appication Programming Interface umumnya disebut sebagai Web Appication Programming Interface Server atau Web Service [8].

\section{h. Format Data}

JSON (JavaScript Object Notation) adalah sebuah berkas yang umumnya digunakan sebagai pertukaran data pada internet. Berkas JSON berbasis teks sehingga mudah dikenali oleh berbagai macam bahasa pemrograman sehingga sangat ideal untuk digunakan dalam pertukaran data antar aplikasi yang berbeda bahasa pemrogramannya [8].

Sejauh ini format data yang paling populer memang XML, namun demikian JSON jelas sekali tumbuh popularitas dan penggunaannya. Banyak developer lebih suka menggunakan JSON, karena berbagai alasan, diantaranya:

1. Data bisa diakses tanpa parsing yang rumit

2. JSON parser tersedia hampir di semua bahasa pemrograman

3. JSON parser cepat, kecil, ringan dan tidak rumit penggunaannya

4. Output JSON lebih kecil karena tidak perlu mencantumkan attribute dan namespace, selain itu tag yang digunakan hanya berupa kurung kurawal.

\section{HASIL DAN PEMBAHASAN}

Perancangan sistem dilakukan dengan menggunakan flowchart yaitu bagan yang memperlihatkan urutan prosedur dan menggambarkan ruang lingkup aplikasi serta bagaimana aplikasi tersebut berkerja. Beberapa fitur yang ada pada aplikasi ini adalah pencarian film, edit informasi film, hapus film dan pemutar film.

\section{a. Proses Pencarian Film}

Pada tahap pencarian film, user mencari sebuah film dengan memasukkan judul film pada textbox yang tersedia kemudian diproses dan akan ditampilkan beberapa suggestion film yang ditemukan berdasarkan inputan judul. Setelah itu user memilih salah satu film untuk mencari informasi lengkapnya. Saat proses simpan, sistem akan melakukan pengecekan terlebih dahulu apakah ada judul yang sama atau tidak. Jika ada film yang sudah tersimpan maka akan muncul peringatan bahwa film sudah tersimpan, jika tidak ada informasi yang sama sebelumnya maka ketika disimpan akan masuk ke database dan muncul di daftar film pada menu utama. Ditunjukkan pada Gambar 1 Flowchart Pencarian Film.

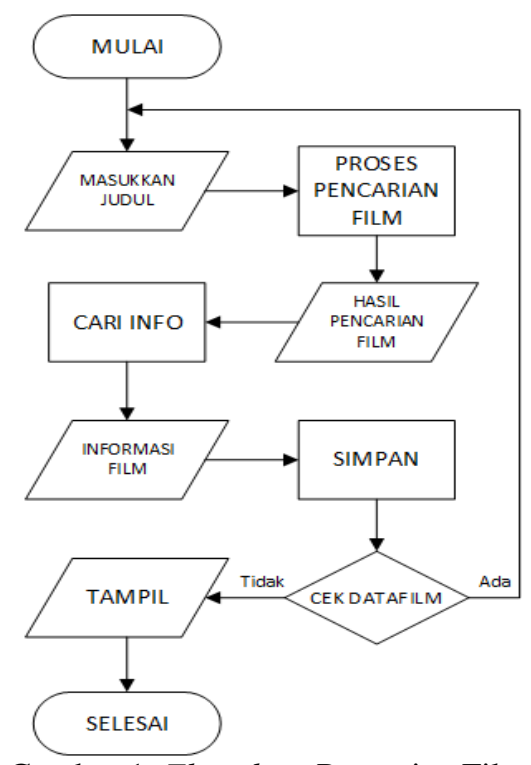

Gambar 1. Flowchart Pencarian Film.

\section{b. Proses Edit Informasi Film}

Pada tahap edit informasi film, user dapat melakukan edit informasi pada suatu film yang terdapat pada daftar film di menu utama dengan mengklik tombol edit informasi film. Kemudian informasi yang dapat ditambahkan adalah catatan pada film dan file film yang tersedia di harddisk, ditunjukkan pada Gambar 2. Flowchart Edit Informasi Film. 


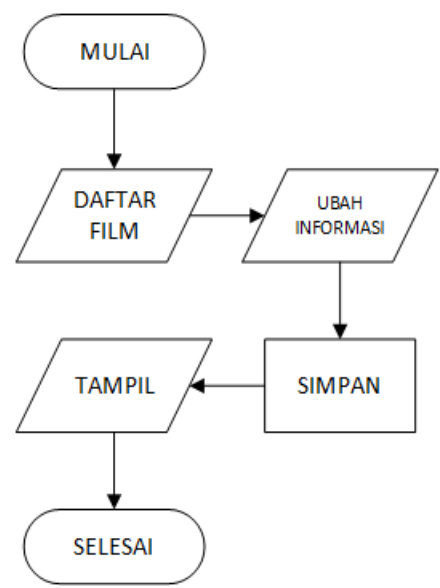

Gambar 2. Flowchart Edit Informasi Film.

\section{c. Proses Hapus Film}

Pada tahap proses hapus film, user dapat menghapus film yang sudah tersimpan pada database. Diawali dengan memilih film yang terdapat pada daftar film di menu utama, kemudian tekan tombol delete pada keyboard, maka akan muncul konfirmasi data yang akan dihapus dan ada pilihan hapus film ya atau tidak. Jika ya maka film akan terhapus, jika tidak akan kembali ke daftar film, ditunjukkan pada Gambar 3. Flowchart Hapus Film.

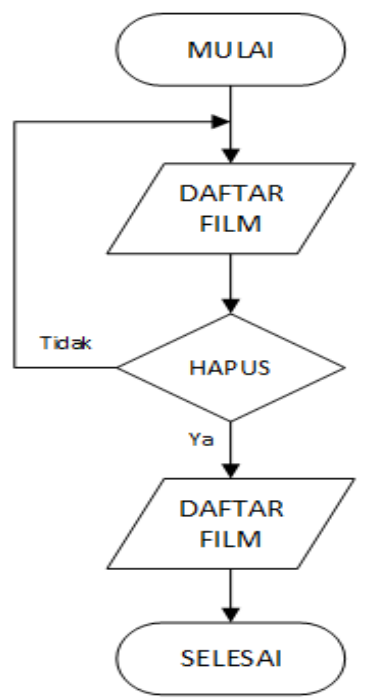

Gambar 3. Flowchart Hapus Film.

\section{d. Proses Putar Film}

Pada tahap putar film, user dapat memutar film yang ada pada daftar film di menu utama, yang sebelumnya file film ini dapat ditambahkan secara manual pada proses edit informasi film dengan memasukan path film yang tersedia pada harddisk dengan mengklik tombol browse. Jika pada saat proses putar film tidak ada file yang tersedia maka akan muncul peringatan belum ada file video dan kembali ke menu utama. Jika file tersedia, maka film akan tampil dengan menggunakan Media Player GOM. Proses ditunjukkan pada Gambar 4 Flowchart Putar Film.

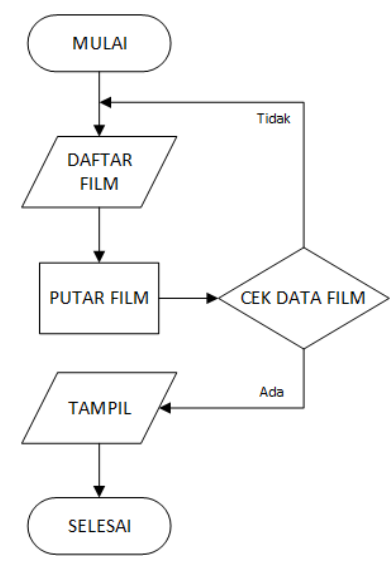

Gambar 4. Flowchart Putar Film

\section{PENGUJIAN SISTEM}

Pengujian sistem dilakukan dengan metode Black Box yang meliputi, uji pencarian film, uji pencarian informasi film dan simpan, uji edit informasi film dan simpan, pengujian putar film dan pengujian hapus data.

\section{a. Uji Pencarian Film}

Pada pengujian pertama yaitu uji pencarian film, user memasukkan judul film "harry" kemudan dengan mengklik tombol Cari Film maka hasil yang muncul adalah beberapa rujukan film yang berhubungan pada teks judul inputan. Pada proses pencarian film ini sistem melakukan request judul ke url http://www.omdbapi.com/?s=harry yang hasilnya ditunjukkan pada Gambar 5 Menu Pencarian Film.

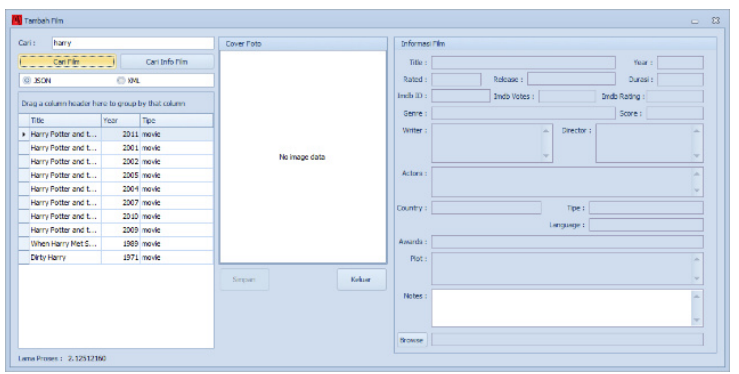

Gambar 5. Menu Pencarian Film

Dalam request ini, sistem akan mengambil data keluaran dari website imdb melalui omdbapi dan data yang diambil hanya berupa judul film. Response yang didapat berupa format JSON (JavaScript Object Notation) yang kemudian akan diparsing ke dalam bentuk tabel, dan ditampilkan pada data grid.

\section{b. Uji Pencarian Informasi Film dan Simpan}

Selanjutnya setelah uji pencarian film, langkah kedua adalah mencari informasi pada film yang dipilih. Pada pengujian ini, user memilih salah satu film yang ada pada tabel hasil pencarian film, kemudian dengan mengklik tombol cari info film maka hasilnya adalah berupa output cover poto dan beberapa informasi mengenai film tersebut. Proses 
pencarian informasi diambil dari imdbID yang di dapat pada proses pencarian film, kemudian sistem akan melakukan request ke url http://www.omdbapi.com/?i=tt1201607.

Sama seperti proses uji pencarian film sebelumnya, hanya saja dalam proses ini yang diambil adalah beberapa informasi film yang dianggap penting dalam penelitian. Hasil ditunjukkan pada Gambar 6. Pencarian Informasi Film

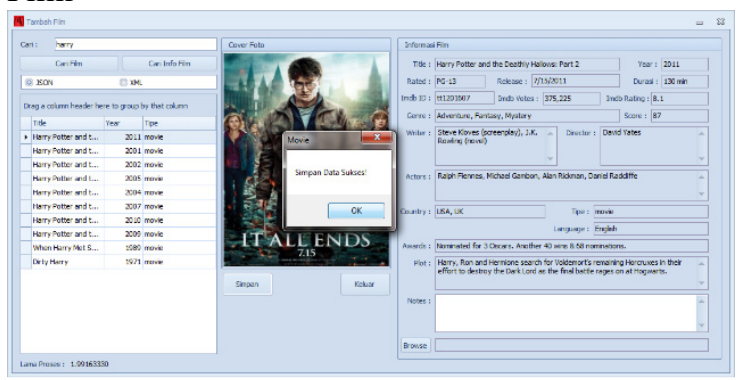

Gambar 6. Pencarian Informasi Film

Setelah disimpan maka akan muncul di halaman utama, seperti yang ditunjukkan pada Gambar 7. Tampilan Menu Utama.

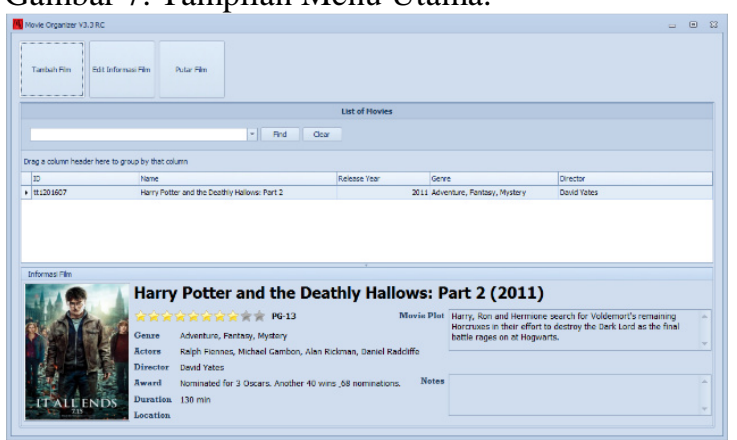

Gambar 7. Tampilan Menu Utama.

\section{c. Uji Edit Informasi Film dan Simpan}

Pada pengujian Edit Informasi Film dan Simpan, user dapat menambahkan catatan atau note mengenai film dan juga bisa menambahkan file film seperti yang ditunjukkan pada Gambar 8 Menu Edit Informasi Film. Untuk memasukkan file film klik tombol browse maka akan tampak seperti pada Gambar 9 Show Dialog dan cari film yang tersedia pada harddisk. Film yang dapat dieksekusi adalah format mp4, flv, mkv, avi, 3gp.

Jika sudah selesai menambah atau mengedit informasi dan menambah file film, kemudian user klik simpan, maka pada aplikasi akan muncul pop up yang mengatakan bahwa update data berhasil seperti yang ditunjukkan pada Gambar 8 Menu Edit Informasi Film.

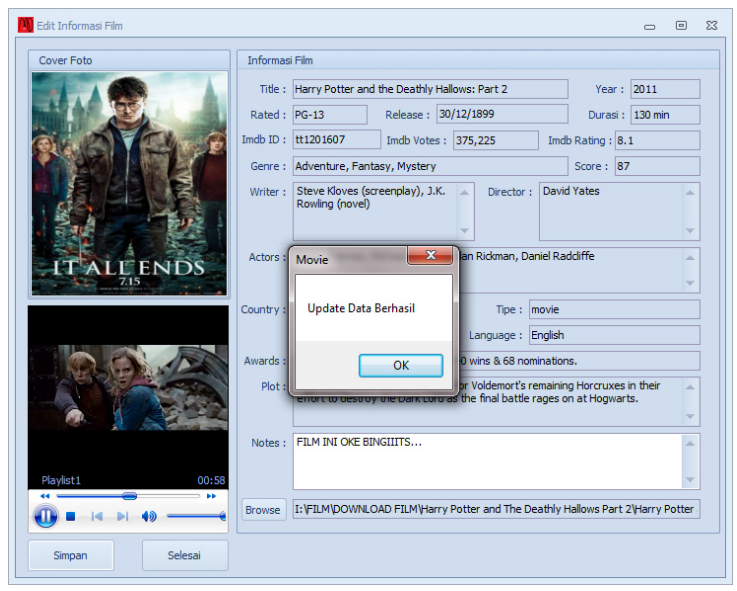

Gambar 8. Menu Edit Informasi Film

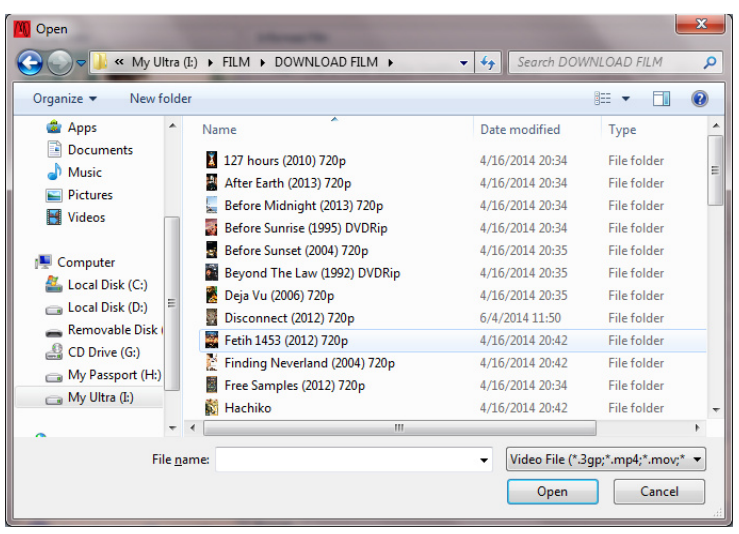

Gambar 9. Show Dialog

Setelah disimpan maka akan muncul di menu utama dan informasi film sudah terupdate sesuai apa yang ditambahkan oleh user. Dapat dilihat pada Gambar 10. Menu Utama Update dibawah ini.

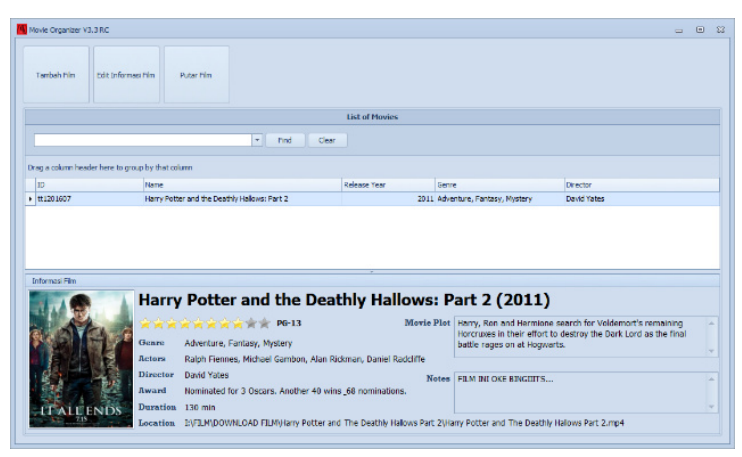

Gambar 10. Menu Utama Update

\section{d. Uji Putar Film}

Pada pengujian putar film, sebelumnya user telah memasukkan file film pada menu edit informasi film, jika sudah ada file film maka ketika diputar dengan menekan tombol enter akan muncul media player seperti ditunjukkan pada Gambar 11 Gom Media Player. 


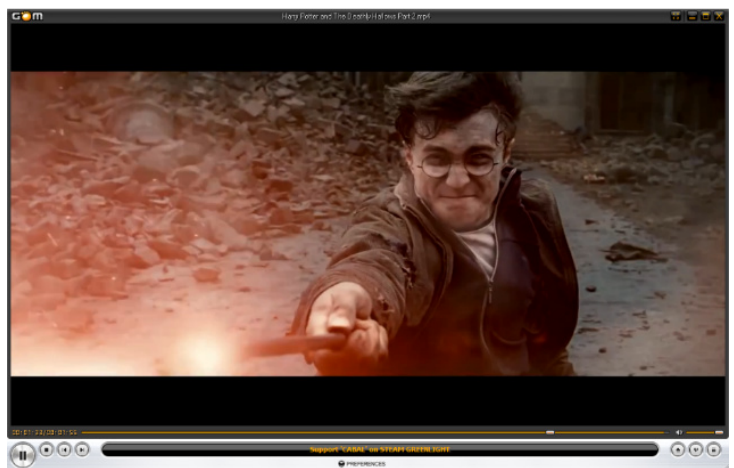

Gambar 11. Gom Media Player

Jika belum ada file film yang ditambahkan sebelumnya oleh user, maka ketika menekan tombol enter pada aplikasi akan muncul pop up yang mengatakan bahwa belum ada file video. Ditunjukkan pada Gambar 12 Konfirmasi Belum Ada File Video.

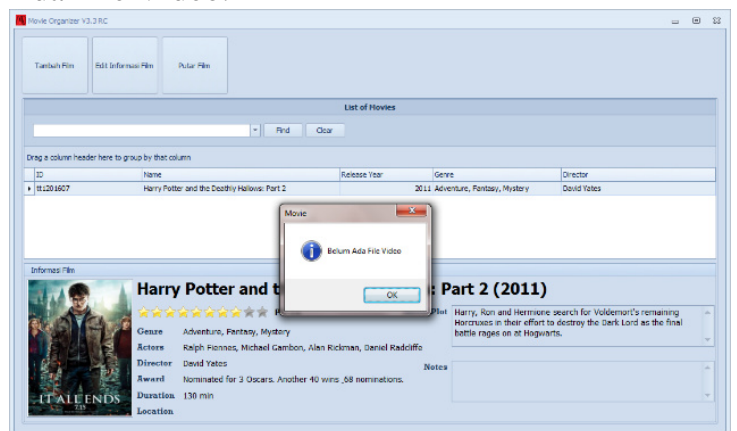

Gambar 12. Konfirmasi Belum Ada File Video

\section{e. Uji Hapus Data}

Pada pengujian hapus data film, user terlebih dahulu memilih film yang ingin dihapus pada daftar film di menu utama, setelah film dipilih (ditandai dengan highlight) kemudian data film dapat dihapus dengan menekan tombol delete pada keyboard, maka akan muncul pop up yang berisi konfirmasi data yang akan dihapus dan ada pilihan hapus film Yes atau No. Ditunjukkan pada Gambar 13 Konfirmasi Hapus Data.

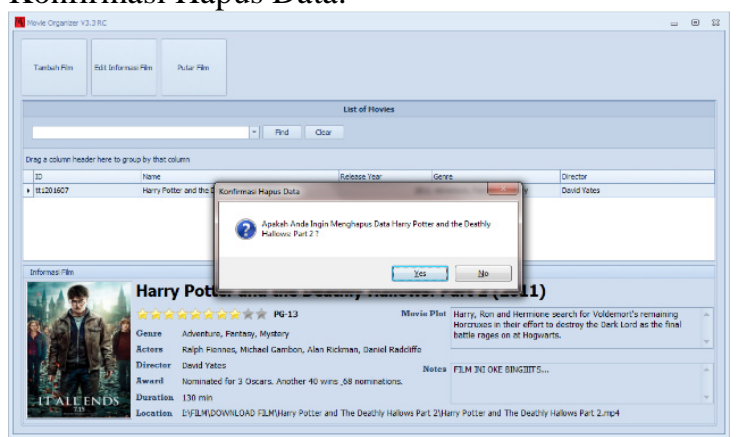

Gambar 13. Konfirmasi Hapus Data

Setelah user klik Yes maka akan muncul lagi pop up data telah dihapus, seperti yang ditunjukkan pada Gambar 4.18 Pop Up Hapus Data. Kemudian user klik OK dan kembali ke menu utama.

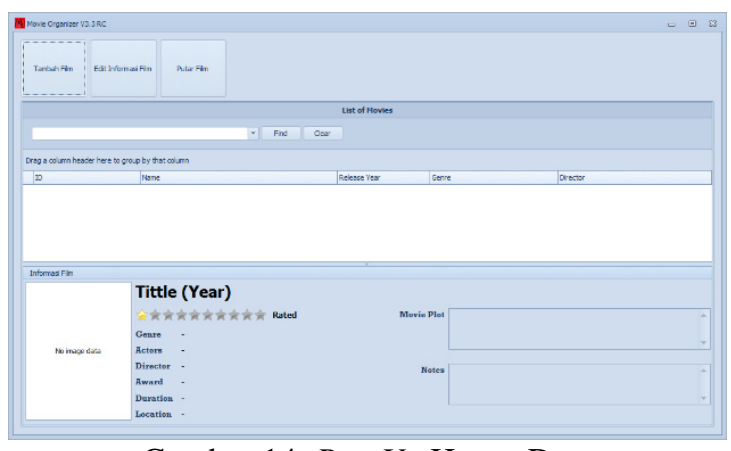

Gambar 14. Pop Up Hapus Data

\section{KESIMPULAN}

Kesimpulan yang dapat diambil berdasarkan penelitian mengenai aplikasi Movie Organizer Menggunakan Teknik Web Scrapping yaitu sudah dapat memberikan informasi dari film yang dicari. Aplikasi juga dapat digunakan secara online (untuk menambah database film) dan offline (untuk melihat dan merubah informasi film) yang bisa membantu kolektor dalam manajemen koleksi film. Teknik web scrapping sudah berhasil diimplementasikan pada aplikasi desktop yang dirancang.

\section{DAFTAR PUSTAKA}

[1] Departemen Pendidikan dan Kebudayaan. 1990. Kamus Besar Bahasa Indonesia. Jakarta: Balai Pustaka.

[2] Miyarso, E. 2009. Developing of Interactive Multimedia for the Study of Cinematography. Graduate School, State University of Yogyakarta. Yogyakarta.

[3] Ensiklopedi Nasional Indonesia. 1990. Jld. V, Jakarta: PT. Cipta Adi Pustaka.

[4] Qalyubi, S dkk. (Ed). 2007. Dasar-dasar Ilmu Perpustakaan dan Informasi. Jurusan Ilmu Perpustakaan dan Informasi Fakultas Adab. Yogyakarta.

[5] Terry, G. R. \& Rue, Leslie W. Rue. 2010. Dasar-dasar Manajemen. (Terje: G.A. Ticoalu). Jakarta: Bumi Aksara.

[6] Zaira, Z. 2011. Implementasi Ekstraksi Web Untuk Hadits Yang Diterjemahkan Dalam Bahasa Indonesia. Jurusan Teknik Elektro. Fakultas Teknik Universitas Indonesia. Depok.

[7] Hardjono, D. 2007. Pengembangan Aplikasi Database Dengan Microsoft Access 2007. Yogyakarta: Andi.

[8] Sena, S. A. 2013. Perancangan dan Pembuatan Application Programming Interface Server untuk Arduino. Jurusan Teknik Elektro Fakultas Teknik Universitas Brawijaya. Malang. 